\title{
Ischaemic neuropathy in uraemic patients caused by bovine arteriovenous shunt
}

\author{
C. F. B O L T O N, A. A. DR IE D G ER, A N D R . M . L I N D S A Y \\ From the Departments of Clinical Neurological Sciences, Medicine and Radiation Oncology, \\ Victoria Hospital, University of Western Ontario, London, Ontario, Canada
}

SUMMARY A bovine shunt, inserted between the radial artery and cephalic vein in the upper arm for access during chronic haemodialysis, caused a distal, ischaemic neuropathy in two patients. There were electrophysiological signs of axonal degeneration of motor and sensory nerve fibres in the patient with severe ischaemia, and, of only sensory fibres in the patient with mild ischaemia. Thenar muscle blood flow studies using ${ }^{133} \mathrm{Xe}$ were a useful measure of altered tissue perfusion. Recovery was incomplete in both cases, despite banding of the graft and improved tissue perfusion in the severe case.

A "vascular steal" syndrome (Storey et al., 1969; Bussell et al., 1971; Lindstedt and Westling, 1975; Ringden et al., 1976) may complicate CiminoBrescia fistulae, an anastomosis between the radial artery and cephalic vein in the forearm used for access in chronic haemodialysis. Patients experience transient pain, numbness, and tingling on the radial side of the hand during each dialysis procedure. Although said to be rare (Lindstedt and Westling, 1975), these symptoms occurred in two-thirds of patients reported by Warren and Otieno (1975) who ascribed the symptoms to a transient carpal tunnel syndrome resulting from venous engorgement and oedema distal to the fistula. However, Harding and Le Fanu (1977) suggested that nerve ischaemia was an additional factor, since one of their patient's symptoms was partially relieved by ligating the radial artery to prevent retrograde arterial flow, before sectioning of the flexor retinaculum in this, and a second patient, relieved symptoms completely. Although ischaemic cutaneous ulcers were noted in another patient (Ringden et al., 1976), persisting nerve ischaemia has not, to our knowledge, been reported.

Several of our patients being dialysed by a bovine shunt (calf carotid artery) between the

Address for reprint requests: Dr C. F. Bolton, Department of Clinical Neurological Sciences, Victoria Hospital, 391 South Street, London, Ontario, Canada N6A 4G5.

Presented in part at the Fourth International Congress on Neuromuscular Diseases, Montreal, Canada, 17-21 September, 1978.

Accepted 6 March 1979 brachial artery and cephalic vein in the upper arm complained of numbness and tingling throughout the hand during the dialysis procedure, suggesting that there was diffuse, but transient, nerve ischaemia. Two patients developed persisting ischaemic neuropathy immediately after insertion of the graft. These two cases are reported to emphasise the risk of such events, to document the clinical and electrophysiological features of local ischaemia of peripheral nerve in uraemic patients, and to demonstrate how radioactive xenon $\left({ }^{133} \mathrm{Xe}\right)$ muscle blood flow measurements assess the altered perfusion induced by the shunt.

\section{Methods}

Our two patients were among 60 from the renal unit who had bovine shunts. Because of this and other complications we have stopped using this type of shunt.

Motor and sensory nerve conduction studies using surface electrodes, and electromyography using a concentric needle electrode, were performed according to standard techniques.

The method of Lassen et al. (1964) which used ${ }^{133} \mathrm{Xe}$ was adapted to study thenar muscle blood flow. Both hands were exercised to fatigue or ischaemic pain by repetitive fist clenching. Exercise was not performed when ischaemic pain was present at rest. Immediately upon completion of exercise, $800 \mathrm{nCi}$ of ${ }^{133} \mathrm{Xe}$ in $0.1 \mathrm{ml}$ of saline were injected into the thenar muscle of each hand through a fine needle, and the needle then with- 
drawn. Data collection, by imaging with a gamma camera, began immediately and continued for 10 minutes. The data were fed into a computer at a framing rate of 0.1 second. Regions of interest were defined about the activity visualised in each hand, and the time curves of remaining ${ }^{133} \mathrm{Xe}$ activity displayed on a semi-logarithmic plot (Figure). The rate of ${ }^{133} \mathrm{Xe}$ washout was derived from the slope. If the patient had been exercised,

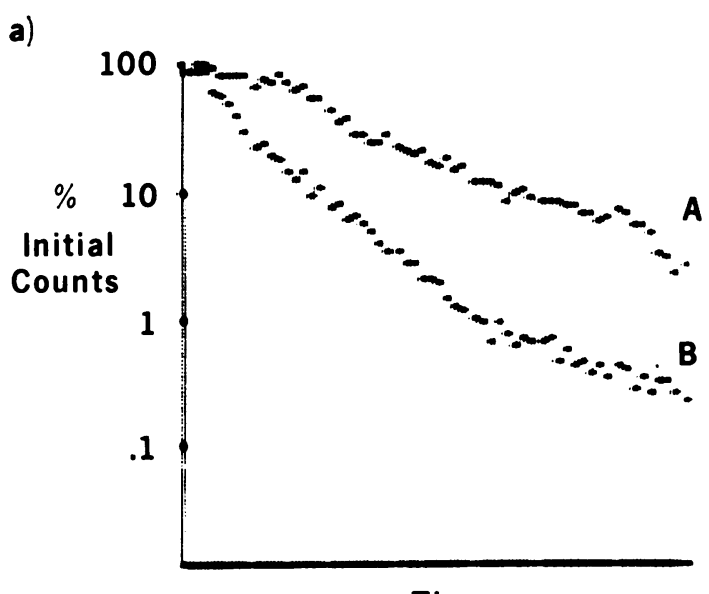

b)
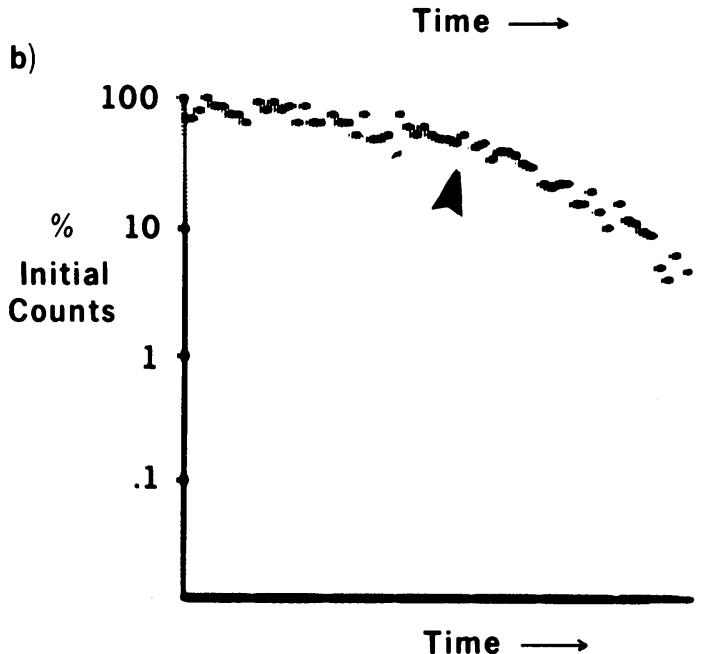

Figure Washout curves during 10 minutes after thenar muscle injection of ${ }^{13} \mathrm{Xe}$ in case 1 (see Table). Upper graph (a) shows the washout curve for the shunt side $A$, and the normal side $B$, when ischaemia was moderate. Note the initially rapid, post-exercise washout followed by a slower resting rate. Lower graph (b) shows the curve on the side of the shunt when ischaemia was marked. The more rapid washout phase followed manual compression of the shunt (arrow). the initial slope was steep relative to the final slope, and the two slopes were used to determine maximal and rest blood flow respectively. A useful variant of the method was to follow the basal flow estimation with manual shunt compression to assess the magnitude of the steal (Table).

\section{Results}

CASE 1

A 58 year old woman had a bovine graft inserted between the left brachial artery and cephalic vein in the upper arm for access during chronic haemodialysis. She immediately noticed severe weakness of forearm and hand muscles, numbness below the mid forearm, and a burning sensation in the hand which occurred spontaneously and on light touch. The burning sensation was much worse during each dialysis procedure. The hand was slightly cold and cyanosed. The radial and ulnar pulses were absent at the wrist, returning partially with manual pressure on the graft. Neurological examination two weeks later showed that the deep tendon reflexes were normal but the forearm and hand muscles were severely weak. Below the mid forearm there was a total loss of immediate pain sensation but preservation of delayed pain sensation and partial loss of touch sensation. At the digits, there was moderate loss of vibration sense, preservation of position sense, and absence of two-point discrimination.

Six weeks after insertion of the shunt there was sudden worsening, purplish discolouration appearing in the skin between the first and second digits, and total loss of sensation developing below the mid forearm except for preservation of delayed

Table Thenar muscle blood flow in uraemic patients $\left({ }^{133} \mathrm{Xe}\right.$ method, $\left.\mathrm{ml} / 100 \mathrm{~g} / \mathrm{min}\right)$

\begin{tabular}{|c|c|c|c|c|c|}
\hline & \multirow{2}{*}{$\begin{array}{l}\text { Time after } \\
\text { shunt } \\
\text { inserted } \\
\text { (days) }\end{array}$} & \multicolumn{2}{|c|}{ Shunt limb } & \multicolumn{2}{|c|}{ Opposite limb } \\
\hline & & Rest & Exercise & Rest & Exercise \\
\hline \multirow{5}{*}{$\begin{array}{l}\text { Case 1 } \\
\text { Moderate } \\
\text { ischaemia } \\
\text { Severe } \\
\text { ischaemia } \\
\text { With shunt } \\
\text { compressed } \\
\text { After banding }\end{array}$} & & & & & \\
\hline & 32 & 2.7 & 2.5 & 4.0 & 31.6 \\
\hline & 41 & 0.7 & - & 2.3 & - \\
\hline & 41 & 3.4 & - & - & - \\
\hline & 43 & 7.1 & - & 4.4 & - \\
\hline \multicolumn{3}{|l|}{ Case 2} & 1.6 & 1.9 & 6.7 \\
\hline $\begin{array}{l}\text { Results in } 13 \\
\text { uncomplicated } \\
\text { Cimino-Brescia } \\
\text { arteriovenous } \\
\text { fistulae } \\
\text { (Lindstedt, 1972) }\end{array}$ & & \multicolumn{2}{|c|}{$3.7 \pm 0.465 \pm 8$} & \multicolumn{2}{|l|}{$4.7 \pm 0.7$} \\
\hline
\end{tabular}


pain sensation. The forearm and hand muscles were totally paralysed, and the brachioradialis reflex was absent. A spontaneous burning pain in the hand was worsened by light touch. Median and ulnar nerve conduction studies showed no motor or sensory response, from surface electrodes at the thenar and hypothenar muscles and index and little fingers, respectively, on wrist stimulation. The elbow region could not be stimulated because of pain near the site of the graft. The radial nerve sensory response, recorded antidromically at the wrist, was also absent. Needle electrode studies two weeks later when there had been some return of forearm strength showed, in the left abductor digiti minimi and extensor carpi radialis muscles, a moderate number of fibrillation potentials and a severe reduction in the total number of motor unit potentials, many being polyphasic; the triceps and deltoid muscles were normal. The electrophysiological findings were consistent with axonal degeneration, most severe distally, in motor and sensory fibres of median, ulnar, and radial nerves.

A mild uraemic polyneuropathy was evident from neurological examination and from motor and sensory conduction studies of nerves in the opposite and lower limb.

Thenar muscle and blood flow studies (Table and Figure) were initially consistent with severe reduction of muscle blood flow as a result of the graft. In order to improve tissue perfusion caused by excessive arteriovenous shunting, the graft was banded six weeks after the fistula had been inserted, increasing muscle blood flow. Normal temperature and colour immediately returned to the hand, discolouration of the index and middle fingers disappeared, and pulsation in the radial and ulnar arteries returned. However, neurological improvement was slow and incomplete. Sixteen months later the patient still experienced continuous, uncomfortable numbness, tingling, and burning distal to the elbow, worsened by light touch. All muscles supplied by the radial, median, and ulnar nerves below the elbow were severely wasted and weak. Position sense and two-point discrimination were lost in the hand. Light touch, pain, and temperature were preserved partially below the elbow. Vibration was absent in the fingers, moderately impaired at the wrist, and mildly impaired at the elbow. The brachioradialis reflex was absent. Sweating was absent below the elbow but limb colour was normal and there was no tissue swelling. Skin temperature of the left hand was $32.9^{\circ} \mathrm{C}$ and of the right, $33.2^{\circ} \mathrm{C}$.

Follow-up of median nerve conduction studies showed the thenar muscle action potential still absent at two and a half months. It returned to
$13 \%$ of the value in the opposite limb at three and a half months, and to $35 \%$ at 16 months. There was essentially no change in latency. The results were similar for ulnar nerve conduction studies. Evoked sensory action potentials in the median, ulnar, and radial nerves remained absent. The $F$ response latency, tested in the median nerve distribution, also remained absent. Needle electrode study of the first dorsal interosseous muscle at $\mathbf{1 6}$ months showed a few fibrillation potentials and only one motor unit potential on attempted full voluntary contraction.

Thus, while muscle blood flow studies suggested that there had been considerable improvement in tissue perfusion, clinical and electrophysiological studies indicated that there had been only mild axonal regeneration in motor and sensory nerve fibres, less than would be expected if this had been a healthy limb. The uraemic state, only partially controlled by haemodialysis, and possible persisting tissue ischaemia, may both have contributed to the delayed recovery.

CASE 2

A 50 year old woman had a bovine graft inserted in the right upper arm. Neurological examination and sensory and motor nerve conduction studies, including median nerve conduction studies of the right arm, were previously normal. She immediately noticed numbness and tingling in all surfaces of the right hand, most noticeable in the little finger and thumb. There was no impairment of strength, pain or discomfort, but the numbness persisted. On the second day, she noted severe burning pain in the hand, present only during the single dialysis performed that day and not during later procedures.

Examination 10 days after insertion of the shunt revealed good pulses and skin nutrition. The neurological examination, in particular all sensory modalities, and median and ulnar motor nerve conduction velocities, were normal. However, there was a $33 \%$ reduction, to $8 \mu \mathrm{V}$, in the amplitude of the median nerve evoked sensory action potential recorded from the index finger (it had been $26 \mu \mathrm{V}$ before the graft was inserted), and a $43 \%$ reduction, to $12 \mu \mathrm{V}$, in the ulnar nerve evoked action potential from the fifth finger, the percentages representing comparisons with the opposite limb. The sensory action potential latencies were normal. The right radial nerve sensory action potential at the wrist was absent. The findings were consistent with partial, subclinical, axonal degeneration of sensory nerve fibres.

Thenar muscle blood flow performed 16 days after insertion of the shunt showed no significant 
abnormality at rest, but there was no response to exercise of the affected limb (Table, the relatively low response in the opposite limb was probably the result of inadequate exercise). However, it was decided not to band the graft in this patient.

The numbness in the hand disappeared spontaneously six weeks later. Conduction studies at 20 months showed no change, except that the median nerve sensory action potential amplitude had increased slightly to $42 \%$ of the opposite limb. Thus, despite symptomatic recovery, there was only minimal electrophysiological recovery.

\section{Discussion}

While the bovine shunt has not been studied extensively for vascular effects, the Cimino-Brescia arteriovenous fistula has. Blood flow is increased in the forearm but reversed distally in the radial artery, and blood pressure in the thumb is reduced (Lindstedt, 1972). While Lindstedt and Westling (1975) report ${ }^{133} \mathrm{Xe}$ thenar muscle blood flow is not decreased in most patients, possibly because of a compensatory increase in flow through the distal vascular bed, effective arterial pressure in muscle was decreased in one of their patients who had a radial steal syndrome. Ringden et al. (1976) reported on 83 patients with Cimino-Brescia fistulae. One developed arterial insufficiency from excessive arteriovenous shunting and four, venous insufficiency from venous thrombosis. All five patients showed structural changes in skin nutritional arteries. These ischaemic symptoms and signs were reversed by either closure of the fistula for venous insufficiency, or ligation of the radial artery for arterial insufficiency.

The vascular effects of a shunt may not explain entirely nerve dysfunction in uraemic patients since several observations have suggested that nerves in uraemia are unusually susceptible to ischaemia. The reports of Popovtzer et al. (1969) and Romagnoni and D'Amico (1970) each describe a patient whose polyneuropathy improved after bilateral nephrectomy had suddenly improved severe hypertension. Both reports proposed that high renin levels before nephrectomy had caused vasoconstriction of vasa nervorum. A similar mechanism was suggested by Meyrier et al. (1972) to explain a mononeuritis multiplex developing in three patients after rapid ultrafiltration dialysis had been used to treat excessive oedema, the ultrafiltration presumably causing "massive release of catecholamines and renin." Castaigne et al. (1972) have shown that, in limbs of uraemic patients made ischaemic by a tourniquet, evoked sensory nerve action potentials persisted longer than in control subjects, an effect which could be reversed by macromolecular perfusion, and enhanced by a single dialysis. This transient effect, related to plasma volume factors, suggests an abnormality of cell membranes in uraemia.

The bovine shunts in our patients were located in the upper arm where considerable arteriovenous shunting probably occurred. This may be the "watershed area" of vasa nervorum in the upper limb (Dyck et al., 1972), making shunts more likely to cause ischaemia in this location than in the distally located Cimino-Brescia fistula. Exercise did not result in a rise of thenar muscle blood flow, in contrast to Cimino-Brescia fistulae in which a normal rise occurs (Lindstedt, 1972; Table). While it is not yet possible to measure peripheral nerve blood flow in man, such measurements in cats reveal a lack of autoregulation (Smith et al., 1977). If this situation applies to man, the above noted vascular effects would be even more likely to induce nerve ischaemia. Moreover, all of these factors, plus the fall in the partial pressure of oxygen (Aurigemma et al., 1977) and of systemic blood pressure known to occur regularly during each haemodialysis procedure, may explain the paraesthesiae distal to fistulae or shunts experienced by several of our patients, transiently, during each procedure.

Whether the involvement of sensory nerve fibres, and relative sparing of motor fibres, in our mild case means that sensory fibres are more susceptible to ischaemia is speculative. The causalgic syndrome in the severe case suggests that nonmyelinated nerve fibres may be affected in severe nerve ischaemia. In both cases, the reduction in amplitude of action potentials with little effect on latencies indicates a predominantly axonal degeneration. Needle electrode studies in the severe case showed distal muscle to be more severely denervated, indicating mainly distal axonal degeneration. Greater susceptibility of distal nerve segments to diffuse ischaemia, or more severe ischaemia distally, are two possible explanations of this observation. In the mild case, symptoms disappeared spontaneously, demonstrating the capacity for some recovery. However, in the severe case, this recovery was less than expected, even after tissue perfusion had been enhanced by banding of the graft. The ${ }^{133} \mathrm{Xe}$ thenar muscle blood flow studies in both cases provided a measure of tissue perfusion (Table).

Patients on chronic haemodialysis usually show only a stabilisation of uraemic neuropathy, despite an adequate haemodialysis programme (Bolton et al., 1977), in contrast to the greater improve- 
ment with successful renal transplantation (Bolton et al., 1971). Thus, the incomplete recovery of nerve function in both of our cases might be expected, even without considering the possibility of persisting nerve ischaemia.

We thank Mrs K. Carter, EMG technician, and Miss Betsy Toth, secretary.

\section{References}

Aurigemma, N. M., Feldman, N. T., Gottlieb, M., Ingram, R. H., Lazarus, J. M., and Lowrie, E. G. (1977). Arterial oxygenation during hemodialysis. New England Journal of Medicine, 297, 871-873.

Bolton, C. F., Baltzan, M. A., and Baltzan, R. B. (1971). Effects of renal transplantation on uremic neuropathy: a clinical and electrophysiologic study. New England Journal of Medicine, 284, 1170-1175.

Bolton, C. F., Lindsay, R. M., and Linton, A. L. (1977). Uremic neuropathy in patients on different hemodialysis schedules. Neurology (Minneapolis), 27, 396.

Bussell, J. A., Abbott, J. A., and Lim, R. C. (1971). A radial steal syndrome with arteriovenous fistula for hemodialysis. Annals of Internal Medicine, 75, 387-394.

Castaigne, P., Cathala, H. P., Beaussart-Boulenge, L., and Petrover, M. (1972). Effect of ischaenia on peripheral nerve function in patients with chronic renal failure undergoing dialysis treatment. Journal of Neurology, Neurosurgery, and Psychiatry, 35, 631-637.

Dyck, P. J., Conn, D. L., and Harud, O. (1972). Necrotizing angiopathic neuropathy: three dimensional morphology of fibre degeneration related to sites of occluded vessels. Mayo Clinic Proceedings, 47, 461-475.

Harding, A. E., and Le Fanu, J. (1977). Carpal tunnel syndrome related to antebrachial Cimino-
Brescia fistula. Journal of Neurology, Neurosurgery, and Psychiatry, 40, 511-513.

Lassen, N. A., Lindbjerg, J., and Munck, O. (1964). Measurement of blood flow through skeletal muscle by intramuscular injection of Xenon-133. Lancet, 1, 686 .

Lindstedt, E. (1972). Studies in therapeutic arteriovenous fistulae. Scandinavian Journal of Urology and Nephrology, Supplement, 14.

Lindstedt, E., and Westling, H. (1975). Effects of an antebrachial Cimino-Brescia arteriovenous fistula on the local circulation in the hand. Scandinavian Journal of Urology and Nephrology, 9, 119-124.

Meyrier, A., Fardeau, M., and Richet, G. (1972). Acute asymmetrical neuritis associated with rapid ultrafiltration dialysis. British Medical Journal, 2, 252-254.

Popovtzer, M. M., Rosenbaum, B. J., Gordon, A., and Maxwell, M. H. (1969). Relief of uremic polyneuropathy after bilateral nephrectomy. New England Journal of Medicine, 281, 949-950.

Ringden, O., Fagrell, B., Friman, L., and Lundgren, G. (1976). Subcutaneous arteriovenous fistulas for dialysis with special emphasis on vascular insufficiency. Scandinavian Journal of Urology and Nephrology, 10, 73-79.

Romagnoni, M., and D'Amico, G. (1970). Neuropathy in uremia. New England Journal of Medicine, 282, 1271.

Smith, D. R., Kobrine, A. I., and Rizzoli, H. V.气 (1977). Absence of autoregulation in peripheral $\mathbb{D}$ nerve blood flow. Journal of the Neurologicalo Sciences, 33, 247-352.

Storey, B. J., George, C. R. P., Stewart, J. H., Tiller D. J., May, J., and Sheil, A. G. R. (1969). Embolic and ischemic complications after anastomosis of radial artery to cephalic vein. Surgery, 66, 104.

Warren, D. J., and Otieno, L. S. (1975). Carpal tunnel syndrome in patients on intermittent haemodialysis. Postgraduate Medical Journal, 51, 450-452. 